\title{
A LANGUAGE GAME WITH PRECEDENT PHENOMENA
}

\author{
Ksenia Balysheva ${ }^{1 *}$, Elena Romanova ${ }^{2}$, Maria Romanova ${ }^{3}$ \\ ${ }^{1}$ Associate Prof. Dr. Mari State University, RUSSIAN FEDERATION, qsuaka@mail.ru \\ ${ }^{2}$ Associate Prof. Dr. Mari State University, RUSSIAN FEDERATION, romanowaud@yandex.ru \\ ${ }^{3}$ Associate Prof. Dr. Mari State University, RUSSIAN FEDERATION, romasch@mail.ru \\ ${ }^{*}$ Corresponding author
}

\begin{abstract}
This paper is devoted to a language game with precedent phenomena. By precedent phenomena the authors mean well-known texts, easily recognized and reproduced in the minds of native speakers. This paper describes precedent phenomena of a phraseological level such as set expressions, idioms, proverbs. These elements are often transformed to draw the addressee's attention and serve as the basis for creating a language game. A language game refers to the intentional breach of habitual use of words and set expressions which demonstrates the author's creative ability to deviate from the normative and stereotypical use. The purpose of this deviation is to express the additional denotative and connotative meanings.

The materials of the research include texts of modern fictional prose, mass media and advertisements. The methods of contextual, semantic and structural analysis were used to discover the types of precedent phenomena transformation. The main types of precedent phenomena transformations include the following: 1) change of size of a precedent phenomenon; 2) change of structure of a precedent phenomenon; 3 ) formation based on an analogy, according to a commonly known model; 4) transformation of elements of set expressions without replacing them; 5) transformation of meaning based on polysemy and homonymy of elements.

The given types of transformation specify and specialize semantically the original set expressions, proverbs, phraseological units to fit them into a certain situation. It is the author's individual interpretation that the transformed set expressions, phraseological units and proverbs acquire emotional-evaluative connotations, produce additional influence effects on the reader and convey a wide range of emotions.
\end{abstract}

Keywords: language game, precedent phenomena, set expression, phraseological unit, transformation.

\section{INTRODUCTION}

In modern conditions we observe a change in a language feeling together with dynamic changes of people's lifestyle. Publicistic writing, fictional prose and real conversation are filled with new words and expressions, a considerable part of which is represented by precedent phenomena. 
A precedent phenomenon is a primary pattern phenomenon, which is set for evaluation and comparison for the purpose of creating a secondary pattern phenomenon based on the pattern that already existed (Kovalev, 2004, p. 57). As a rule, a precedent text is well-known and of temporary type. It must be easily recognized by most of recipients and must correspond to primary goals of text creation.

Precedent phenomena are considered precedent for a certain social group (e.g., for teachers, students, retired people), for a nation (e.g., for the Russians, the Germans, the English, the Americans) or they can be universal, common for many cultures (e.g., Napoleon and Hitler). A detailed analysis of precedent phenomena, typical of different social groups is given in the works by V.V. Krasnyh (2002), G.G. Slyshkin (2000, 2004), Mieder (2010), Romanova (2014).

At present the following types of precedent phenomena are widely studied: a precedent situation, a precedent name, a precedent text, a precedent utterance (see Gudkov, Zakharenko, Krasnyh, Bagaeva, 2007). The focus of this paper is on precedent utterances.

A precedent utterance is "a reproduced product of verbal and cogitative activity", "a complete and selfcontained unit, which can be predicative or not", a complex sign, whose sum of meanings is not equal to its general meaning, i.e. its general meaning is always broader than a plain sum of its meanings. Consistent with the work of V.V. Krasnyh we refer quotations from different types of text, proverbs, set expressions, phraseological units to precedent utterances (Krasnyh, 2002, pp.48-49). It is generally considered that knowledge of precedent texts and utterances is a sign of an individual's belonging to a certain epoch or culture while lack of knowledge of such texts shows individual's detachment from a culture or an epoch.

Precedent phenomena in general, and precedent utterances in particular, are widely used in advertising and mass media, cinematograph, political communication, colloquial speech. Being used in these spheres of communication, precedent phenomena often become objects of a language game, which is aimed at arousing certain associations in an addressee and treating an utterance as a riddle or allusion.

By a language game (a philosophical concept introduced and developed by L. Wittgenstein (2009)) we understand a type of verbal behavior which aids to achieve additional influence effects and is realized with contextual transformation of language means. Consequently, a language game is a purposeful violation of a language norm, which shows the author's creative ability to deviate from normative and stereotypical use of language levels and expresses the additional denotative and connotative meanings (Balysheva, 2010, pp. 141-142). In case of a language game, language units are not used in their common way, but are subject to various types of transformations for the purpose of achieving a strong influence on an addressee.

\section{RESULTS}

In the course of research we analyzed the cases of using a language game with precedent phenomena in fictional prose, advertising and press in the English, Russian and German languages and singled out the main types of precedent phenomena transformation aimed at creating a language game. In the studied texts the authors use widely known proverbs, phraseological units, set expression which are transformed and acquire a new form and meaning. The main types of precedent phenomena transformations include the following: 1) change of size of a precedent phenomenon; 2) change of structure of a precedent phenomenon; 3) formation based on an analogy, according to a commonly known model; 4) transformation of elements of set expressions without replacing them; 5) transformation of meaning based on polysemy and homonymy of elements. With these types of transformation of precedent phenomena the language game effect may arise.

\subsection{A change of size of a precedent phenomenon}

This type of transformation combines such techniques as reduction and expansion of a precedent utterance. In the case of reduction of an original expression one or several of its elements are omitted. Using his/her background knowledge, an addressee will easily recover the meaning and structure of an original expression.

One of the examples of such a transformation is an advertising slogan of the German tourist company "Arosa", which is short, precise and expressive: "Lust auf Schiff?" In this slogan the original German set expression "Lust haben auf etw" is used with the verb omitted. A similar transformation of a phraseological unit "im Einklang mit etw. stehen" is evident in the advertisement of the Weleda cosmetic company: "Weleda: Im Einklang mit Mensch und Natur" (Weleda: In tune with a man and nature). In these two cases the language game effect is not strong enough. The given slogans are elliptical sentences, which are easily reconstructed and have no implication. 
The other subtype of this transformation is an extension of a set expression. With such a type of transformation the meaning of an expression changes, but not considerably, it can also acquire a new shade of meaning.

In the advertising slogan "Wenn das Unmögliche möglich wird, wird die Geschichte geschrieben" we observe that the biblical eloquent expression "Wenn das Unmögliche möglich wird" (make the impossible possible) is continued with "wird die Geschichte geschrieben" (then the history is shaped). The final slogan demonstrates the innovative character of the company's products and their importance for the human history (When the impossible becomes possible, then the history is shaped).

The famous German proverb "Erst die Arbeit, dann das Vergnügen" (literally, "First work, then pleasure", similar to the English proverb "Business before pleasure") is extended in the advertisement for "Mazda" and is transformed into a rhetorical question "Ist das noch Arbeit oder schon das Vergnügen?" (Is it still business or already pleasure?) The question form highlights how fine the line between work and pleasure is in a good car.

In the sentence "Love is blind, but marriage is a real eye opener", which serves as the title for the book by K. Lette, the extension of the phraseological unit is observed (Lette, 2013). The use of the occasional noun eye opener, built according to the same model as the nouns bottle opener, tin opener, can opener, in the extended phraseological unit makes the original phraseological unit contextually precise and adds a new meaning, so that we understand the title of the book: no matter how blind love can be, marriage will put everything in its place and will show what real things are like.

In some cases precedent set expressions and phraseological units are extended through turning a simple word into a compound word. This is the case with the German advertisement of the iMac company in which the set expression "das Zeug zu etw. haben» (have a giftttalent for smth.) is extended when the component "Werk-" is added to the noun "Zeug" (talent, gift). So the extended set expression gets a new form in the company's advertisement and a language game arises: "Denn Apple hat das Werkzeug, um Digitalbilder auf völlig neue Weise zu speichern". As a result of using a compound noun, we understand the advertisement in two ways: "Apple has a device / a talent to save digital photos in an absolutely new way".

The worldwide-known "Nokia's" slogan is extended to express gratefulness to a friend in the Russian book "Beemine" by M. Sveshnikova. The language game here is based on simultaneous realisations of direct and indirect meanings in the context: "... to Nickolai Aleshin, a person compared to a Nokia phone, as he is connecting people" (Sveshnikova, 2007, p. 5).

\subsection{A change of structure of a precedent phenomenon}

This type of transformation provides substitution of any component in the structure of a precedent phenomenon.

We observe this transformation in one of "Nivea's" slogans: "Schlafen Sie sich schön" (Sleep till you are beautiful) (Romanova, Savina, 2016, p. 204). The transformed phrase correlates with the set expression "Schlafen Sie sich aus" (Sleep well), in which the verb prefix aus is replaced by the adjective schön (beautiful).

In the proverb "Ende gut. Alles gut" (literally, "The end is good. All is good", similar to the English proverb "All's well that ends well") the first component was replaced by the noun Preise to advertise a German supermarket: "Preise gut. Alles gut» (Prices are good. All is good). Similarly the first component was replaced by the noun Essen in the advertisement of another German company: "Essen gut, alles gut" (Food is good. All is good).

Another example of this type of transformation is observed in the slogan of a German building company. In the original set expression "sein Leben leben" the noun Leben (life) is replaced by the noun Zunkunft (future), so with the new form of the set expression the slogan "Weberhaus: die Zukunft leben" (Weberhaus: Live you future) the innovative approach of the company is underlined.

The phraseological unit "Love at first sight" has elements being replaced in the names of chapters of the book "Love is blind but marriage is a real eye-opener": "Lust at first sight"; "Hate at first sight"; "Love at second sight" (Lette, 2013, pp. 25, 35, 101). These titles help the reader to observe the main character's evolution of feelings. Replacing the third component believing by the adjective with the negative meaning disbelieving in the title of one of the chapters of this book - "Seeing is disbelieving" (compare it with the original phraseological unit "Seeing is believing") the author aims at showing that even seeing things doesn't make the main character believe them or even if she sees things she doesn't believe them. 
A good example of replacing the second element in a phraseological unit is given in the same book by $\mathrm{K}$. Lette: "I suppose your legal eagle fella just expects you to worship the water he walks on" (Lette, 2013, p. 52). The replacement of the noun ground by the noun water in the sentence intensifies the degree of reverence of the object. According to the Bible Jesus Christ could walk on water, so in this context the main character is expected to match her boyfriend to the god. The transformed phraseological unit shows how much she should admire the man and makes the reader smile.

In the novel "Anna and the French Kiss" by S. Perkins the set expression "happy birthday" is transformed by replacing the second element with the concordant noun Friday and extending its structure: "I won't wish you happy birthday. Or even a belated happy Friday." - "Oh, you can wish me happy Friday. I have no objection to Fridays" (Perkins, 2010, p. 51). The transformed expression being repeated several times in the conversation given before produces a humorous effect on the reader.

The authors of modern Russian fictional prose often resort to English proverbs, set expressions, quotations and slogans in their books. One of such examples is observed in the book "Duhless" by S. Minaev, when the author replaces the noun death by the noun morning and the bride and groom's vow "till death do us part" turns into "till morning do us part" (Minaev, 2006, p. 265). The refreshed vow depicts precisely the nature of casual relationship.

\subsection{The formation based on an analogy, according to a commonly known model}

In this type of transformation new author's individual phrases are constructed according to models of wellknown proverbs, set expressions, and quotations. It means that the original syntactical structure is preserved, but the lexical filling is changed. As a result we observe syntactical parallelism of the original and the transformed expressions. The use of this technique specifies the meaning of a commonly known precedent phenomenon and the effect of a language game is achieved.

This type of transformation is widely used in modern Russian fictional prose. The gradual lexical change of the proverb "My home is my castle" results in the opposite statement "The castle is my home": "My office is my castle. My home is my office. The castle is correspondingly my office home" (Dontsov, 2009, p. 89).

The transformed proverbs or antiproverbs based on the syntactical structure of traditional proverbs are particularly frequent in novels about the Russian office reality. E.g., in the transformed proverb "Don't go with your work record book to someone else's shogunate" (Minaev, 2008, p. 125) we recognise the Russian proverb "Don't go to with your own rules to someone else's monastery", which corresponds to the English proverb "When in Rome do as the Romans do" with the same meaning. Or, in the proverb describing relations in the office "A natural competition and mobbing are just one step apart" (Naryshkin, 2008, p. 36) the original proverb "Love and hate are just one step apart" is evident. A precedent utterance for another "office" proverb "A hand sees a hand at a far distance" (Minaev, 2008, p. 128) is the Russian proverb " $A$ fisherman sees a fisherman at a far distance", which English equivalent is "Birds of a feather flock together".

The construction of a new phrase according to a commonly known model is also widely spread in advertising. E.g., the set phrase "we do all we can", used in advertising, is taken as a model for a slogan "We drink all we can, the rest we sell". In this slogan the transformed phrase underlines a particularly good quality of the drink the company produces. Another model which is actively used in advertising is the model "Noun? No, thank you". Being first used in the slogan of anti-nuclear energy campaign of the1980-s ("Atomkraft? Nein, danke!" - "Nuclear energy? No, thank you!"), the model usually has a noun fitting the situation in the question, while the idiom "No, thank you!" remains unchanged: "Herpes? Nein, danke!" (Herpes? No, thank you!); "Werbung? Nein. danke!" (Advertising? No, thank you!).

\subsection{Transformation of elements of set expressions without replacing them}

The most common technique of this type of transformation is the change of degrees of comparison of adjectives. This technique is frequently used in German advertising, when they stress that the advertised product is of a higher quality than the others. E.g., the phraseological unit "hohe/große Ansprüche stellen" (set high requirements) in the advertisement of the Nivea cosmetic company is transformed into the address to a customer: "Stellen sie höhere Ansprüche" (Set higher requirements). Another example of this type is the use of the adjective zarte (sweet) in structure of the expression "zarte Versuchung" (sweet temptation) in the superlative degree in the advertisement of chocolate: "Die zarteste Versuchung, seit es_Schokolade gibt" (The sweetest temptation since chocolate appeared).

Transformation of a noun into the affectionate diminutive form is effective in achieving addresser's aims and has a certain influence on an addressee. E.g., the advertisement of the Florena cosmetic company states the following slogan: "Stiftung Warentest bestätigt: Mit Florena habe ich ein glückliches Händchen!" This 
sentence is based on the precedent phraseological unit "eine glückliche Hand haben" (literally, have a lucky/light hand $\rightarrow$ bring luck). With the siffix -chen the noun Hand in addition to the diminutive meaning acquires the seme "tenderness" since hands are being taken care of and the whole sentence means: "Association for quality control proves: With "Florena" I have a lucky tender hand)".

\subsection{Transformation of meaning based on polysemy and homonymy of elements}

We refer cases with semantic remotivation and semantic transformation of precedent phenomena to this type of transformation. This transformation is realised without formal changes, when the context defines the meaning of a word but not a phraseological unit. E.g., the slogan of a German tourist agency "Sie werden doch nicht baden gehen?" can be understood in two ways: "Won't you go down?" or "Won't you go swimming?", because the indirect meaning of the expression baden gehen "go down, meet with failure" is replaced by its direct meaning "go swimming".

A similar effect appears in the slogan of the Financial Times' German edition: "Wir schreiben, womit sie rechnen müssen." The expression "mit etwas rechnen", which has an indirect (reckon with smth.) and direct (count with smth.) meaning, imparts a double interpretation to the slogan: "We write and you will have to reckon with it" or "We write with what you count".

The idiomatic expression "less is more" is used as the slogan in the advertising campaign for the new Sporty KIA Rio three-door edition, which used to be the five-door model. The direct and idiomatic meanings mingle and give rise to a language game: the car has fewer doors now, but more advantages. In the German advertising campaign for Axe black deodorant the same expression (weniger ist mehr) is used for the similar purpose and accentuates reconsideration of the meaning of the original expression: you can apply less deodorant, but its effect will be greater.

Another interesting example of a language game is based on transformation of the English idiom "easy come, easy go". Transformation of the given type becomes possible because of the homonymy of the word easy in English and Russian: the English adjective easy sounds similar to the Russian proper name of the Jewish origin Easya, which is widely used in anecdotes about the Jewish people. Due to the homonymy the English idiom is literally understood and reinterpreted in Russian: "That's how a new story began. The story, in which I was nicknamed Easya. Easy come - easy go. Easya came - Easya went further" (Sveshnikova, 2007 , p. 9). The new expression created by the author of the book loses its aphoristic character and idiomaticity, thus its components can be replaced by more suitable ones fitting a particular context.

Homonymous grammar forms can also cause transformation of precedent phenomena. We can observe it in the advertising slogan of a German online shoe shop "Schrei vor Glück". The first component of the slogan can be treated as a noun or as a verb in the imperative mood, so it can mean either "A scream with happiness" or "Scream with happiness". A similar process is evident in the advertisement of the Bild newspaper. The slogan "Bild dir deine Meinung" is based on the German phraseological unit "seine Meinung bilden" (form an opinion) with the verb bilden in the imperative mood (bild), which coincides with the name of the newspaper. Polysemy of the form Bild and its double meaning give rise to a language game.

\section{CONCLUSIONS}

As the research has shown, a language game with precedent phenomena occurs in texts of different genres: fictional prose, advertising and press. The described types of precedent phenomena transformations (change of size and structure of a precedent phenomenon; formation based on an analogy, according to a commonly known model; transformation of elements of set expressions without replacing them; transformation of meaning based on polysemy and homonymy of elements) are found in English, German and Russian while transformation of set expressions without replacing them is more actively used in German.

The transformed utterances undergo structural or content modification to achieve specific pragmatic effects, intrigue the addressee and arouse her/his emotional response. A language game defies associative stereotypes of linguistic signs perception. It represents reciprocal creativity of the addresser and the addressee, since the addresser needs creativity to make a new utterance, and a certain activity for its decoding is required on the part of the addressee. The author doesn't choose to simply give a ready-made set expression or proverb, but modifies, renews or breaches their habitual usage to make them more catching and attracting attention with an unexpected intellectual novelty. All the cases of a language game demonstrate the author's intentions to specify and specialize semantically the original set expressions, proverbs, and phraseological units to fit them into a certain situation. It is the author's individual interpretation that the transformed set expressions acquire emotional-evaluative connotations and convey a wide range of 
emotions. In the case of a language game, the author is aimed at achieving expression and producing a humorous, ironical or jocular effect on the reader.

A language game with precedent phenomena can be considered today's style dominant, typical of modern mass media, advertising and fictional prose.

\section{REFERENCE LIST}

Balysheva, K.A. (2010). Language Democratisation in Mass Fictional Prose at the end of the $20^{\text {th }}-$ the beginning of the $21^{\text {st }}$ century. Ph. D. thesis in Philological Studies.

Gudkov, D.B., Zakharenko, I.V., Krasnyh, V.V., Bagaeva, D.V. (1997). Some Peculiarities of Precedent Utterances Functioning. Bulletin of Moscow State University, Vol.9. Philology. No. 4.

Dontsov, A. (2009). "The office".

Kovalev, G. F. (2004). A Proper Name as a Precedent in Advertising. Bulletin of Volgograd State University. Philology, Vol.1.

Krasnyh, V.V. (2002). Ethnopsycholinguistics and Cultural Linguistics.

Lette, $\mathrm{K}$ (2013). Love is blind but marriage is a real eye opener.

Matveeva, T.V. (2003). Learner's Dictionary: Language, Speech Culture, Stylistics, Rhetoric.

Mieder, W. (2010). Spruchschlösser (ab)bauen: Sprichwörter, Antisprichwörter und Lernsprichwörter in Literatur und Medien.

Minaev, S. (2008). The Telki.

Minaev, S. (2006). Duhless.

Naryshkin, M. (2008). Downshifter.

Perkins, A. (2010). Anna and the French Kiss.

Romanova, E.V., Okhotnikova E.A. (2011). Structural and Semantic Peculiarities of Modern German Antiproverbs. Topical Issues of Cognitive Linguistics. Proceedings of International Academic Conference.

Romanova, M.S., Savina, A.N. (2016). Linguistic Characteristic of Morphology and Syntax of Cosmetic Products Advertisements. Modern Technologies in Foreign Language Teaching. Proceedings of International Academic Conference.

Slyshkin, G.G. (2000). Linguocultural Concepts of Precedent Texts in Mind and Discourse

Slyshkin, G.G. (2004). Linguocultural Concepts and Metaconcepts.

Sveshnikova, M. (2007). Beemine.

Wittgenstein, L. (2009). Philisophical Investigations 